\title{
GIUSEPPE CARIDI, Carlos III. Un gran rey reformador en Nápoles y España, La Esfera de los libros, Madrid, 2015.
}

El libro del profesor Caridi aparece en Italia en 2014 y un año más tarde fue publicado por la editorial La esfera de los libros. Imparte Historia del Mezzogiorno en la Escuela Superior de Lenguas Extranjeras en Regio Calabria. Es un especialista en los estudios del Mezzogiorno desde la Edad Media hasta el siglo XIX. El libro se divide en dos partes, dedicadas al reinado de Nápoles y a la etapa española. Ocho son los capítulos dedicados al joven Carlos que madura como rey en Italia mientras que dedica siete al rey ya experimentado que llegó a Madrid tras la muerte de su hermanastro.

En el primer capítulo, se hace hincapié en la influencia de Isabel de Farnesio sobre su marido. Se muestra a un Felipe $\mathrm{V}$ débil e indolente, manipulado por su esposa. Es interesante el retrato del profesor Caridi sobre la educación del infante, que no estaba Ilamado a reinar y que no fue la más adecuada para un futuro soberano. También se explica todo el proceso de complejos movimientos de ajedrez para intentar colocar a Carlos en algún trono italiano. Esto se verá sobre todo tras la caída de Alberoni en desgracia.

En el segundo, además de mostrarse la dependencia de Carlos con respecto a sus padres y sus órdenes, se verá cómo con el estallido de la Guerra de Sucesión Polaca se lanzará una campaña contra Nápoles y Sicilia y cómo se hará Carlos con estos territorios. El autor señala cómo los únicos que se beneficiaron fueron Italia, al lograr un príncipe nacional y Carlos, que obtuvo el ansiado trono. Sin embargo, España puso las tropas y los recursos para no obtener nada. Aunque Carlos fuese el rey, quien tenía el gobierno efectivo era un hombre de confianza de los reyes de España, el conde Santisteban del Puerto y más tarde el conde de Montealegre. Casi se puede hablar de protectorado español sobre Nápoles. Carlos no será más que una figura simbólica.

En el caso de Santisteban, veremos más adelante, que el control era tan agobiante que incluso le (mal) asesoró a la hora de mantener relaciones sexuales con su esposa, María Amalia de Sajonia. El autor señala varios rasgos del carácter del monarca, como su paternalismo o la afición por la caza y el campo, quizá como remedio natural ante el riesgo de padecer algún trastorno psiquiátrico como su hermanastro y su padre. Este paternalismo y afabilidad con las personas de su círculo, aunque fueran sirvientes, será una constante a lo largo de la vida del rey. Carlos tuvo un primer momento de gran entusiasmo a su llegada, 
debido al descontento por el gobierno de los austriacos en el territorio. Sin embargo, el autor recoge testimonios de personajes de la época, que explican que son los elementos más bajos de la sociedad napolitana los que se manifestaron con mayor énfasis.

Este tercer capítulo detalla una serie de reformas que se llevarán a cabo en el reino, tanto a la hora de reorganizar las instituciones centrales como las periféricas. Pero siempre bajo la batuta de Santisteban siguiendo los dictados de Madrid. Se aplicará también una planta de secretarías de estado, siguiendo el modelo de Madrid, siendo el hombre fuerte en este periodo el ya citado Santisteban, aunque comenzara a tener la oposición de otro noble español, Montealegre. Mientras que el primero representará un periodo de apenas reformas y de acomodación de la nueva dinastía a los intereses de los grupos privilegiados, el segundo será el momento donde mayor sea el ímpetu reformista en Nápoles. A partir de los diferentes movimientos narrados por el autor para explicarnos el matrimonio de Carlos, será cuando Carlos comience a ejercer, aunque de forma tímida, cierta autonomía en sus acciones.

El cuarto capítulo está dedicado a las reformas que se llevarán con Montealegre, tras la caída de Santisteban y cómo el rey, poco a poco, ira adquiriendo las destrezas de su cargo. El balance de estos intentos reformadores es para el profesor Caridi un fracaso final. Se intentará reducir el poder de los señores en el campo. También nos habla de medidas para impulsar el desarrollo económico de Nápoles, entre ellas la temporal readmisión de judíos para intentar estimular el comercio y que fue un fracaso y la actividad diplomática, incluso con Estambul, lo cual podría despertar recelos en otros estados italianos como Venecia. La unión de los privilegiados que podían ver amenazadas sus prerrogativas los truncarán.

El capítulo quinto se centra en la labor constructora de Carlos, desde palacios y reales sitios a obras públicas, el impulso para la creación de industrias textiles y artísticas. En el caso de los palacios, para darle más prestigio a su joven dinastía. Se da la anécdota de la prohibición de cazar los gatos que mataban faisanes en uno de sus lugares de caza. Pero al no haber felinos, la proliferación de ratas no solo afectaron a las cosechas, también a los bebés que se podían encontrar solos, los cuales eran víctimas de los roedores. Para dar realce internacional a su dinastía, creará la Orden de San Jenaro, la cual fue un fracaso por su poca repercusión final. Es interesante el apartado dedicado a la creación de un ejército y una armada que permitiese a su dinastía mantenerse en el sur de Italia.

El sexto capítulo está dedicado a la Guerra de Sucesión Austríaca y a la importancia de la muerte de Felipe $\mathrm{V}$, momento en el que se puede considerar que Nápoles empieza a tener un soberano de verdad. Nos habla del origen de la contienda y de la supeditación napolitana a los intereses de Madrid, siendo víctima de la amenaza naval británica que demostrará las deficiencias militares del reino y el peligro de un levantamiento proaustríaco contra Carlos. Este momento será el que inicie la caída de Montealegre y la posterior sustitución 
como secretario de estado por Fogliani. Se explica el problema de la Paz de Aquisgrán y la importancia de su artículo séptimo. Su derogación será el principal objetivo de la diplomacia napolitana.

El séptimo nos habla ya de un rey con plenos poderes, sin procónsules que parezcan auténticos reyes. Nos habla del nuevo secretario de estado Fogliani. El autor recoge las opiniones de distintos personajes, que dicen que su nuevo secretario de estado fue su principal error, debido a su poca capacidad. Además, nos habla de las excavaciones en Pompeya y Herculano. Es en este capítulo donde el rey se mostrará especialmente celoso de sus regalías y se negará a que la Inquisición entre en Nápoles. Contrasta esto con lo que se le permitió a la Inquisición hacer a Pablo de Olavide. Será el único momento en el que Carlos se niegue de forma tajante a una petición de la Iglesia que, además, causaba un gran malestar entre la población. En el resto de casos, como la readmisión de judíos o las medidas contra prostitutas y masones, siempre se mostró de acuerdo con dichas peticiones. También aprovecha para hablarnos del ascenso de Leopoldo de Gregorio, más conocido como marqués de Esquilache.

El octavo y último capítulo de esta parte está dedicado a la política exterior y el traslado a España. Se busca por un lado evitar nuevas guerras en Italia y por otro lado, desarmar el artículo Siete de Aquisgrán, según el cual el trono de Nápoles (si Carlos se convertía en rey de España), pasaría a su hermano Felipe en lugar de a su hijo. Para lograrlo, será necesaria una gran labor diplomática a múltiples bandas. En este capítulo también nos habla de los hijos de Carlos y de su esposa, María Amalia de Sajonia. Destaca la mala educación recibida por sus hijos, bien por desgana o por malos preceptores, salvo su hijo Gabriel, al cual el mismo rey le inculcó el interés por las humanidades. También explica la caída del marqués de la Ensenada, relacionada con las filtraciones a Carlos de decisiones de su hermanastro. Finalmente, y tras mantenerse neutral durante su reinado en Nápoles, Carlos al morir Fernando VI, se convierte en nuevo rey de España, como Carlos III.

La segunda de las partes del libro, está dedicada a España. Comienza explicando la subida al trono de Fernando VI y el final de la influencia de Isabel de Farnesio en el nuevo rey. Se destaca el papel pacifista del rey, manteniendo la neutralidad durante la Guerra de los Siete Años. También nos señala la rivalidad entre Ensenada y José de Carvajal y Láncaster y nos vuelve a hablar de la caída del primero. No obstante, la secuencia cronológica del tratado de Límites y de la política exterior con Carvajal y Ensenada está desdibujada, volviendo atrás y adelante en el tiempo. La valoración del sustituto de Ensenada, Ricardo Wall, es positiva, de tal manera que Carlos le mantendrá en el primer gobierno del nuevo rey. Rompiendo con la política mantenida en Nápoles, decide Carlos apoyar a Francia en la Guerra de los Siete Años, aunque no esté preparado el país para dicho enfrentamiento. Es importante remarcar que de Nápoles se trajo no solo a políticos italianos, sino también a españoles que llevaban años sirviéndole en dicho reino. 
El segundo capítulo trata de los primeros años de reinado y de los problemas a los que se tuvo que enfrentar. El continuismo se repitió con casi todos los ministros de su hermano, siendo un equipo que no estaba adaptado a las dinámicas del soberano ni equilibrado. Solo destaca la introducción del marqués de Esquilache y su capacidad de trabajo y diligencia. En éste también se habla de la entrada en la Guerra de los Siete Años y de las deficientes estructuras españolas, que llevaron a la derrota y pérdidas territoriales.

El tercer capítulo se centra en los motivos del Motín de Esquilache, planteando dos hipótesis, la de un "golpe de estado palatino" o un movimiento espontáneo aprovechado por los privilegiados contra Esquilache. El otro gran eje es el de la expulsión de los jesuitas, explicando las causas de la persecución y cómo desde el primer momento se abandonó la vía nobiliaria para seguir la pista eclesiástica.

El cuarto nos habla del ascenso del conde de Aranda y de una característica del rey, como era su paternalismo, que se incardina dentro del Despotismo Ilustrado. Nos ofrece una descripción y un panorama de los diferentes "partidos" o facciones que había en esos momentos. Es ahora cuando se trata uno de los grandes proyectos de Carlos III, que fue el de las repoblaciones de Sierra Morena y de uno de sus responsables, Pablo de Olavide. Se habla de todo el proceso de la traída de personas de centroeuropa y del papel y personalidad del intendente, así como de su caída, acusado de hereje por la Inquisición. Otro de los aspectos a tratar es el intento de modernizar las universidades, con diversos planes de estudios, entre ellos el de Olavide antes de caer en desgracia o de los colegios mayores.

El quinto capítulo nos habla de la lucha por el poder entre el conde de Aranda y Grimaldi. Antes de ser cesado, Aranda pidió la embajada de París. Desde la capital francesa maniobró con elementos del partido aragonés contra el secretario de estado, en especial tras el fracaso de la expedición a Argel de O’Reilly y la múltiple oposición contra el ministro italiano, incluyendo a José de Gálvez. Además de estas cuestiones, se tratará de iniciativas económicas y sociales, como las fundaciones de Asociaciones de Amigos del País. Lo que es importante es señalar el paquete de medidas, con más forma que fondo real, ya que ninguna de ellas trataba de cuestionar el Antiguo Régimen ni el absolutismo de Carlos III, por lo que nunca podrían tener demasiado recorrido, a diferencia de lo que pudo pasar en Inglaterra tras la caída de Jacobo II o posteriormente en Francia tras 1789.

En el sexto capítulo vuelve a hablar de iniciativas económicas, sociales y desarrollo de obras públicas, en este caso, durante al gobierno de Floridablanca. No obstante, Ilama la atención en este capítulo una referencia que hace a quienes defendían la inversión en reformas y obras públicas, frente a aquellos que defendían medidas de austeridad y que ese dinero destinado a las reformas fuese utilizado para pagar la Deuda Pública. Parece que el profesor Caridi intenta establecer un interesante paralelismo entre los seguidores de Keynes y de los Monetaristas. Finalmente, aunque se refiere a iniciativas sociales y económicas, 
desarrolla la cuestión de la Junta de Estado, que es un mecanismo de acción política para coordinar las gestiones de las distintas secretarías.

El séptimo y último capítulo, tiene tres ejes: política exterior, asuntos familiares y la muerte del rey. Nos hablará del Tratado con Portugal y de cómo apoyará a Francia y a las colonias americanas de Inglaterra para intentar recuperar Menorca y Gibraltar. Dentro de la política internacional, se habla de los acuerdos de paz con Marruecos y las regencias de Berbería y de los matrimonios con la dinastía lusa para buscar el acercamiento entre ambos países. En cuanto a los asuntos familiares, se refiere al descontento hacia sus hijos Carlos y Fernando de Nápoles en relación con sus costumbres y a que ambos fueran manejados por sus respectivas esposas. Con relación a su muerte, se vincula con la de su hijo favorito Gabriel, que era el único con inclinaciones culturales. El profesor Caridi habla de una posible depresión que le llevó a la tumba.

En apenas dos páginas se refiere a la muerte del soberano y una pequeña conclusión, ya que no aparece como tal en el presente volumen. Es una pena que un libro de esta extensión y ambición, que pretende hablar del reinado de más de 50 años, si sumamos la etapa napolitana y la española, no tenga una conclusión acorde al proyecto. Si de Carlos III podemos conocer mucho de su reinado español, la época napolitana es la gran desconocida y este libro arroja bastante luz sobre el periodo. Por eso es una pena que el libro no esté rematado con una conclusión, aunque las dos últimas páginas cumplan esa función.

También es una pena que en el libro no aparezca reseñado un apartado donde aparezca toda la bibliografía consultada, teniendo que acudir a las notas para localizar las fuentes del autor. Posiblemente esto haya sido más una decisión editorial que del propio autor. Sin embargo, es interesante el conjunto de láminas de cuadros relacionados con Carlos III tanto en Nápoles como en Madrid.

Aitor Pérez Blázquez Universidad de Málaga 